\title{
COMPARISON BETWEEN ACUTE TOXICITY AND CHEMICAL ANALYSIS OF NATURAL GAS DRILLING EFFLUENT SAMPLES USING PENAEUS MONODON
}

\author{
Yayah Rodiana ${ }^{1,2}$, Daam Settachan ${ }^{2,3}$, Thundorn Saneanukul ${ }^{3}$, Jerry Diamond ${ }^{4}$ \\ (Diterima tanggal 7-7-2011; Disetujui tanggal 2-11-2011)
}

\begin{abstract}
The regulation of point source discharges usually based on specific chemicals which describe thresholds below which no adverse impact on the receiving water. The limitation of this technique includes the fact that it does not take into account interactions among toxicants (e.g. additivity, synergism, antagonism). Therefore, toxicity testing is recommended as integrated approach for identifying toxic pollutants to complement chemical-specific analysis by assessing the sum toxicity of all components in the mixture. The objective of this research was the assessment of Penaeus monodon (PM) as an indicator species for toxicity testing through comparisons between results from 48-h $L C_{50}$ and chemical analysis of the natural gas drilling effluent. Chemical analysis of effluent samples was performed in order to determine concentrations of BTEX (benzene, toluene, ethyl benzene, xylene) and heavy metals $(\mathrm{Cr}, \mathrm{Ni}$, $\mathrm{Cu}, \mathrm{As}, \mathrm{Pb}, \mathrm{Cd}$ ). Average 48-h $\mathrm{LC}_{50}$ 's for PM was $2,94 \%$ for effluent and $0.68 \mathrm{~g} / \mathrm{l}$ for $\mathrm{KCl}$. Comparison between acute toxicity and chemical analysis showed a significant correlation between toluene concentrations and 48- $h$ $L C_{50}$ in $P M(p<0.05)$. No significant correlation was found between the detectable heavy metal concentrations and acute toxicity data in PM. Results suggest that the lack of correlation between toxicity and almost all chemical parameters indicates that toxicity testing is much more useful for monitoring toxicity of effluents than chemical analysis. Additional studies are needed to identify alternative toxicity endpoints as sensitive indicators of impacts on the environments.
\end{abstract}

Keywords: Penaeus monodon, acute toxicity testing, effluent, reference toxicant, BTEX, heavy metal

\section{INTRODUCTION}

Water pollution and more specifically the toxicity of wastewater released into the environment is a serious problem in many developing countries for many reasons. The most obvious is the discharge of wastewater directly into water systems such as rivers, lakes, and oceans, leading to effects on the environment and potentially human health (1).

The wastewater discharges from point sources are called "effluents". Commonly, most of the regulations to control effluent discharges is based on the conventional chemical-specific approach. The usefulness of this approach includes the fact that it is usually less expensive than toxicological and ecological evaluations; can be relatively clearly linked to treatability of individual chemical species that exceed the allowable limits; and human health risks can best be estimated because this approach assesses the concentrations of specific health hazards, such as mercury $(\mathrm{Hg})$, in the effluent. The weakness of this technique includes the fact that it does not take into account interactions among toxicants (e.g. additivity, synergism, antagonism), and the development of standard (i.e. allowable levels

\footnotetext{
${ }^{1}$ Pusat Sarana Pengendalian Dampak Lingkungan-Deputi VII-KLH, Kawasan Puspiptek Gedung 210, Jalan Raya Puspiptek, SerpongTangerang, Banten 15310, Indonesia, nengyayah@yahoo.com.

${ }^{2}$ Indonesian Environmental Toxicology, Chulabhorn Graduate Institute, Bangkok 10210, Thailand

${ }^{3}$ Laboratory of Environmental Toxicology, Chulabhorn Research Institute, Bangkok 10210, Thailand

${ }^{4}$ TetraTech, Inc., Owings Mills, MD 21117, USA
} 
of discharge for all the individual pollutants found in effluent) is very time consuming and resource intensive (2).

In 1984, the U.S.EPA recommended an integrated approach for identifying toxic pollutants that used whole effluent toxicity testing (WETT) to complement chemicalspecific analysis (3). The advantages of WETT include the fact that it can measure the sum effects of complex mixtures of chemicals in effluent (consisting of both known and unknown compounds); the bioavailability of the toxic constituents is assessed and the effects of interactions between constituents are measured; and pollutants for which there are inadequate analytical methods can be addressed. There are also some limitations including the fact that the properties of specific chemicals are not assessed, differences in species sensitivity may lead to different responses in tests with different species, inherent variability of these tests, i.e. intraspecies variability, and the fact that controlled laboratory conditions do not exactly mirror the real receiving environment, also WETTdoes not measure bioaccumulation effects, indirect toxicity effects (effects on a species prey, or long term chronic effects, including endocrine disruption effect) (4).

To estimate toxicity of the effluent, WETT exposes a test population of aquatic organisms such as fish, invertebrates, and algae to diluted and undiluted effluent samples under controlled conditions. At the end of the test, the responses of test organisms e.g. survival, growth, and reproduction are used to estimate the effects of the toxicant or effluent, and then this information is used to regulate the discharge of toxic amounts of pollutants to surface waters.

This technique has been adopted by most regions of the world (5). WETT, known as direct toxicity assessment (DTA) in Australia, was undertaken by Sydney Water in the late 1990s using locally relevant test species; chronic toxicity testing using microalgae (Nitzschia closterium), scallops (Chlamys asperrima aka Mimachlamys asperrima), and acute toxicity testing using Microtox (Vibrio fischeri) and fish larvae (Macquaria sp.) (6).

In Thailand, WETT that has been conducted to probe the acute responses to industrial whole effluent has been done using Giant freshwater prawn (Macrobrachium rosenbergii) (7), while testing with natural gas drilling platform effluent has been done with Black tiger prawn (P. monodon) and Asian Sea Bass (Lates calcarifer $)(8,9)$.

\section{METHODOLOGY}

\section{Experiment design}

All experiments were conducted in the Aquatic Toxicity Testing Unit (ATTU), Environmental Toxicology Laboratory, Chulabhorn Research Institute (CRI), Bangkok-Thailand. The study was conducted in 2 parts.

In part I, the objective was to the measure the 48-h $\mathrm{LC}_{50}$ of PM of the mysis stage (8-10 days) as test organisms. Samples used were effluent from natural gas drilling platforms and reference toxicant (potassium chloride; $\mathrm{KCl}$ ). In Part II, the objective was to compare chemical analysis data with toxicity data, and to see if there is any correlation between acute toxicity and concentrations of any of the chemical components of effluent samples. The samples were used for both chemical and 
toxicity data and came from the same source: 8 effluents from natural gas drilling platforms in the Gulf of Thailand. The chemicals analyzed were benzene, toluene, ethyl benzene and xylene (BTEX) and inorganic (some heavy metals; $\mathrm{Cr}, \mathrm{Ni}, \mathrm{Cu}, \mathrm{As}, \mathrm{Pb}$, and $\mathrm{Cd}$ ) compounds. The toxicity data was derived from $48-\mathrm{h} \mathrm{LC}_{50}$ in PM.

\section{Preparation of reference toxicants}

Quality control for all toxicity tests is done through testing with reference toxicants to monitor inter-batch variations in test organism responses to the same toxicant. The reference toxicant used for acute toxicity testing was potassium chloride $(\mathrm{KCl})$. A $\mathrm{KCl}$ (Merck, Germany) stock solution of $10 \mathrm{~g} / 1$ was prepared in Milli-Q, and in turn diluted with artificial seawater to the following dilution series: 0 (as the control), 0.5, 0.75, 1, 1.5 and $2 \mathrm{~g} / 1 \mathrm{KCl}$.

\section{Preparation of effluent}

The effluent samples were collected in a 1-L cubitainer by the grab sampling method from natural gas drilling platforms. Following the CRI SOP (14), the effluent was diluted with artificial seawater at a dilution series of 0 (as the control), $0.625,1.25,2.5,5$ and $10 \%$ for acute toxicity testing.

\section{Test organisms}

P. monodon was obtained from local commercial hatcheries in Chachoengsao province, Thailand. They were acclimated to the laboratory conditions for $24-\mathrm{h}$ prior to testing. The test organisms were placed in an aerated tray containing artificial seawater and acclimated to the following conditions: dissolved oxygen was maintained above $4.0 \mathrm{mg} / \mathrm{L}, \mathrm{pH}$ at $7.5-8.5$, salinity at $30 \pm 2 \mathrm{ppt}$, temperature at $30 \pm 2{ }^{\circ} \mathrm{C}$, and a photoperiod of 12-h light and 12-h darkness for 24-h prior to initiating testing. They were fed freshly hatched Artemia nauplii twice daily (6:00 and 18:00). Dead or moribund animals were removed from the tray during observations.

\section{Chemical analysis of effluents}

Analysis of heavy metals $(\mathrm{Cr}, \mathrm{Ni}, \mathrm{Cu}, \mathrm{As}, \mathrm{Pb}$, and $\mathrm{Cd}$ ) was done using the acid digestion technique in a closed-vessel microwave system from Milestone Inc., US. Samples were analyzed by inductively coupled plasma mass spectrometry (ICP-MS). Internal standards were used for quality control during analysis. To check for contamination during the digestion procedure and sample measurements, a blank solution was prepared and carried through each set of analyses.

The organic compounds analyzed were benzene, toluene, ethyl benzene, and xylene (BTEX). Samples were prepared by SPME using a 75/ m Carboxen-PDMS fiber from Supelco (Supelco, Bellefonte, PA, USA) (5760). A BTEX standard was purchased from Labor Dr. Ehrenstorfer-Schafers, Germany.

GC-MS analysis was carried out on a Hewlett Packard HP 6890. Headspace Samples $(1 \mu \mathrm{l})$ were analyzed by capillary column (DB-5) gas chromatography using $1 \mathrm{ml} / \mathrm{min}$ helium as the carrier gas and programmable injector was $200^{\circ} \mathrm{C}$, start temperature: $40^{\circ} \mathrm{C} /$ for $5 \mathrm{~min}$, and the final temperature was $200^{\circ} \mathrm{C}$, which was held for $10 \mathrm{~min}$. The gradient was $15^{\circ} \mathrm{C} /$ minute. Known standards were added into the sample to determine percent of recovery. 


\section{Toxicity tests}

Artificial seawater of a salinity of $30 \pm 2 \mathrm{ppt}$ was prepared by mixing sea salts (Coralife Scientific Grade Marines sea salt and Deep Ocean Synthetic sea salts, Energy Saver Unlimited, Inc, Carson-USA) with deionized water, and then aerating for at least $24-\mathrm{h}$ before use. Place $150 \mathrm{ml}$ of test solution into $500 \mathrm{ml}$ plastic containers.

Each container received 10 healthy test organisms randomly selected from the acclimatization tray. Each toxicity test consisted of 4 replicates per concentration. Test chambers were kept in a low-temp incubator under controlled temperature $\left(30 \pm 1{ }^{\circ} \mathrm{C}\right)$ and photoperiod (12-h light: 12- dark) over the period of testing (48-h). Renewal of effluent test solutions was done at $24-\mathrm{h}$, but not for reference toxicant $(\mathrm{KCl})$ solution. Dissolved oxygen, $\mathrm{pH}$, salinity, and temperature were measured daily. At renewal of effluent test solutions (24-h), all measurements were performed prior to and after renewal for effluent samples. The number of live organisms in each test chamber were recorded every 24-h. Dead organisms were removed daily using a clean transfer pipette.

\section{$\mathrm{LC}_{50}$ Calculations}

Acute toxicity of both effluent and reference toxicant was determined by calculating the median lethal concentration $\left(\mathrm{LC}_{50}\right)$ of mysis stage PM using the Toxcalc statistical software package (McKinleyville, California, USA) for PC.

\section{Statistical Analysis of Data}

SPSS software version 17.0 for Windows (Chicago, USA) was used to carry out statistical analysis of the data in this study. Comparison among treatment groups of the $\mathrm{LC}_{50}$, as well as the BTEX and heavy metal concentrations, were analyzed using the t-test or Mann-Whitney test.

\section{RESULTS AND DISCUSSION}

\section{Acute toxicity testing with effluent samples}

Forty-eight hour static renewal toxicity testing was performed using 8 different natural gas drilling effluent samples. Table 1 summarizes the toxicity data $\left(48-\mathrm{h} \mathrm{LC}_{50}\right)$ for the mysisstage PM.

Table 1. Summary of 48-h $\mathrm{LC}_{50}$ data for P. monodon (PM) from tests with natural gas drilling platform effluent

\begin{tabular}{c|c|c}
\hline Date of Experiment & Sample ID & LC50 in PM (\%) \\
\hline $6 / 6 / 09$ & 1 & 1.65 \\
$6 / 6 / 09$ & 2 & 1.85 \\
$27 / 6 / 09$ & 3 & 1.19 \\
$29 / 6 / 09$ & 4 & 2.25 \\
$15 / 7 / 09$ & 5 & 5.04 \\
$15 / 7 / 09$ & 6 & 3.42 \\
$29 / 7 / 09$ & 7 & 2.65 \\
$29 / 7 / 09$ & 8 & 5.47 \\
\hline Mean (\%) & & 2.94 \\
CV (\%) & & 53.8 \\
\hline
\end{tabular}


From the table above, it can be observed that the mean 48-h $\mathrm{LC}_{50}$ from test conducted using the 8 effluent samples was $2.94 \%$ in PM. Additionally, the coefficient of variation $(\mathrm{CV})$ in PM was 53.8. The CV value is used as a measure of test precision, and is calculated by dividing the standard deviation by the mean, and expressed as a percentage (10).

Holdway (2002) reported results of acute toxicity testing with produced water from various oil production areas, with $\mathrm{LC}_{50} / \mathrm{EC}_{50}$ 's ranging from $5 \%-50 \%$ (4). The parameters which affect the various $\mathrm{LC}_{50}$ values may be species-specific, age, and habitat (11).

\section{Acute toxicity testing with reference toxicant}

In general, reference toxicant testing is conducted for 2 purposes. The first is to evaluate the relative health and sensitivities of a particular batch of test organisms, and the second is to track the test performance over time during testing.
The relative health and quality of test organisms from different batches could be assessed through development of a reference toxicant control chart, which plots the $\mathrm{LC}_{50}$ for different batches of 1 test species to 1 reference toxicant over time. Typically, control chart limits use the mean \pm two standard deviations, and a minimum of 5 data points to develop the first set of limits (12). Two standard deviations below the mean is the lower control limit (LCL), while two standard deviations above the mean is the upper control limit (UCL). Test organism response to the reference toxicant is considered acceptable in the range between the LCL and the UCL.

Control charts were established as shown in figures 1 to monitor the performance (possibly due to relative health and interbatch sensitivities) of test organisms from 5 tests. The control chart limits (mean $\pm 2 \mathrm{SD}$ ) for mysis-stage $P$. monodon ranged from $0.58-0.78 \mathrm{KCl}$.

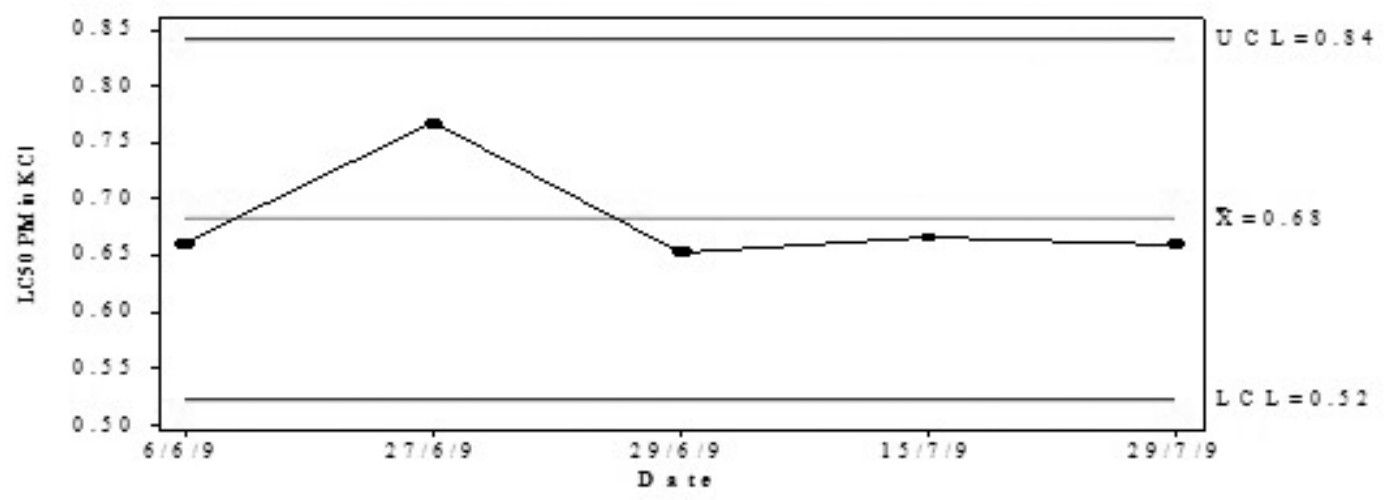

Figure 1. P. monodon (mysis-stage) control chart showing the average $\mathrm{LC}_{50}$ with upper and lower control limits 
From this study, the reference toxicant data from 5 tests using $\mathrm{KCl}$ in $\mathrm{PM}$ were within the control chart limits. This means that all the $\mathrm{LC}_{50}$ data from tests with natural gas drilling platform effluent, which were conducted, using test organisms from this same batch, are acceptable.

\section{Chemical analysis of BTEX compounds}

Results are presented as benzene, toluene, ethyl benzene, $\mathrm{x}$-xylene and the sum of $\mathrm{m}$ - and p-xylenes, because these isomers show similar response and recovery. The summary of the BTEX data for the effluent is shown in Table 2.

In all effluent samples, the concentration of benzene is highest relative to toluene, ethyl benzene and xylene. Each compound did not show the same trend with respect to samples, i.e. the highest concentrations for different compounds were observed in different effluent samples. The range of benzene is 381-10227 $\mathrm{ng} / \mathrm{ml}$, with the lowest concentration observed in Sample 3 and the highest in Sample 7, respectively. A different trend was observed for toluene, with the lowest concentration observed in Sample $1(5.59 \mathrm{ng} / \mathrm{ml})$ and the highest in Sample $5(4572 \mathrm{ng} / \mathrm{ml})$. For ethyl benzene, the range of concentrations is 1.91 - $152 \mathrm{ng} / \mathrm{ml}$, with the lowest concentration observed in Sample 1 and the highest in Sample 6, respectively. Similarly, for $o$-xylene and $m, p$-xylene, Sample 6 had the highest concentrations, while Sample 4 had the lowest. The range of $o$-xylene is $3.39-338 \mathrm{ng} / 1$ and for $m, p$-xylene is $5.29-244 \mathrm{ng} / \mathrm{ml}$, respectively. For quality control during measurement of BTEX, recovery (\%) was in the acceptable range of $81.5-99.5 \%$. Most of the data were significantly above the instrument detection limits for the respective compounds, with only a few data points being close to the detection limits, particularly for ethyl benzene.

Table 2 Summary of concentrations of BTEX compounds in effluent samples (ng/ml)

\begin{tabular}{cccccc}
\hline SAMPLE ID & BENZENE & TOLUENE & ETHYL BENZENE & O-XYLENE & M\&P-XYLENES \\
\hline 1 & 2362 & 5.59 & 1.91 & 11.21 & 17.14 \\
2 & 2413 & 11.59 & 2.15 & 13.79 & 21.08 \\
3 & 381 & 20.95 & 2.62 & 26.49 & 39.66 \\
4 & 1784 & 161 & 45 & 3.39 & 5.29 \\
5 & 8510 & 4572 & 38 & 6.91 & 14.57 \\
6 & 1633 & 1133 & 152 & 338 & 244 \\
7 & 10227 & 950 & 14.94 & 76.91 & 86.29 \\
8 & 2813 & 1052 & 9.58 & 65.14 & 84.37 \\
\hline RECOVERY (\%) & 81.45 & 86.96 & 95.44 & 99.48 & 97.68 \\
IDL (NG/ML) & 0.99 & 1.49 & 1.84 & 1.86 & 1.96 \\
\hline
\end{tabular}

$\mathrm{IDL}=$ Instrument detection limit 


\section{Chemical analysis of heavy metals}

The summary of the concentrations of heavy metals analyzed in the effluent samples is shown in Table 3.

For heavy metals, Arsenic (As) was detected in all effluent samples with higher concentrations than the other metals of interest (range: 47-4247 ppb). The highest concentration of As was found in sample 7 (4247 ppb). A detectable concentration of $\mathrm{Cr}$ was found in effluent samples 3, 4, 5, 6 and 8, while the rest of the samples were below the instrument detection limit. Three effluent samples $(3,6$, and 8) had detectable levels of $\mathrm{Ni}$ with the highest concentration found in effluent sample 6 (3.25 ppb). Cu was detectable only in Sample
$3(56.8 \mathrm{ppb})$. Concentrations of $\mathrm{Pb}$ and $\mathrm{Cd}$ were below the detection limit for all effluent samples. For quality control of measurements, percentage of recovery (\% Recovery) was good, ranging from $76.42-94.04 \%$.

\section{Determination of relative influence of different BTEX and heavy metal concentrations on effluent sample toxicity}

The correlation between chemical concentrations in the effluents and the associated toxicity data $\left(\mathrm{LC}_{50}\right)$ in the two test species was analyzed using the Spearman's rho non-parametric method since the data was found not to be normally distributed. The result of the correlation conducted using PM data is shown in Table 4.

Table 3. Summary of heavy metal concentrations in effluent samples (ppb)

\begin{tabular}{ccccccc}
\hline Sample ID & $\mathrm{Cr}$ & $\mathrm{Ni}$ & $\mathrm{Cu}$ & $\mathrm{As}$ & $\mathrm{Pb}$ & $\mathrm{Cd}$ \\
\hline 1 & $\mathrm{ND}$ & $\mathrm{ND}$ & $\mathrm{ND}$ & 988 & $\mathrm{ND}$ & $\mathrm{ND}$ \\
2 & $\mathrm{ND}$ & $\mathrm{ND}$ & $\mathrm{ND}$ & 922 & $\mathrm{ND}$ & $\mathrm{ND}$ \\
3 & 1.60 & 1.65 & 56.80 & 47 & $\mathrm{ND}$ & $\mathrm{ND}$ \\
4 & 0.93 & $\mathrm{ND}$ & $\mathrm{ND}$ & 996 & $\mathrm{ND}$ & $\mathrm{ND}$ \\
5 & 0.51 & $\mathrm{ND}$ & $\mathrm{ND}$ & 171 & $\mathrm{ND}$ & $\mathrm{ND}$ \\
6 & 0.65 & 3.25 & $\mathrm{ND}$ & 322 & $\mathrm{ND}$ & $\mathrm{ND}$ \\
7 & $\mathrm{ND}$ & $\mathrm{ND}$ & $\mathrm{ND}$ & 4247 & $\mathrm{ND}$ & $\mathrm{ND}$ \\
8 & 1.15 & 0.31 & $\mathrm{ND}$ & 2850 & $\mathrm{ND}$ & $\mathrm{ND}$ \\
\hline Recovery (\%) & 89.41 & 89.23 & 89.01 & 94.04 & 76.42 & 87.29 \\
Detection limit & 0.15 & 0.25 & 0.25 & 0.15 & 0.15 & 0.15 \\
\hline
\end{tabular}

nd $=$ Below detection limit

Table 4. Results from Spearman's rho non-parametric test for correlation between effluent BTEX concentrations and $P$. monodon $\mathrm{LC}_{50}$ data

\begin{tabular}{cccccc}
\hline \multicolumn{7}{c}{ Spearman's rho correlations } \\
\hline benzene & toluene & Ethyl benzene & o-xylene & m,p-xylene & nd \\
Correlation Coefficient & .548 & $.857^{* *}$ & .571 & .238 & .238 \\
Sig. (2-tailed) & .160 & .007 & .139 & .570 & .570 \\
\hline
\end{tabular}

** Correlation is significant at the 0.01 level (2-tailed). 
From the results summarized in the table above, it is observed that only toluene yielded a statistically significant correlation with toxicity data (48-h $\left.\mathrm{LC}_{50} ; p<0.05\right)$. This is in agreement with Korn et al. (1981) who stated that toluene is more toxic than many other hydrocarbons, such as benzene, though the latter are more water-soluble. It is expected that the acute toxicity of platform effluent to marine organisms is low, and due to the characteristic of organic compounds, they may be readily lost by weathering but are relatively more toxic in waters that are relatively stagnant and chronically polluted (13).

In terms of results from animal studies (mammalian), acute or repeated exposure to BTEX is expected to produce neurological impairment and could lead to altered ion transport, enzymic activities, and neurotransmitter receptor functions which are necessary for normal nerve impulses and regeneration of action. However, there is currently no mechanistic data for BTEX compounds in aquatic species. Relatively little is known about the abundance or presence of
BTEX compounds in the marine environment, especially in biota, and their behavior in the marine ecosystem.

The Spearman's rho test was also selected to determine if there was a significant correlation between effluent heavy metal concentrations and toxicity data in either test species. Result for PM is summarized in Tables 5. Cd and $\mathrm{Pb}$ data were dropped from the correlation analysis since the concentrations of the 2 metals in all effluent samples were below the detection limits. From the results summarized above, no significant correlation was found between any of the effluent heavy metal concentrations and the toxicity data (48-h $\left.\mathrm{LC}_{50} ; p>0.05\right)$. In most cases, there should not be expected to be a direct relationship between the metal concentration and the measured effects, because, in seawater, dissolved trace metals are partitioned in equilibrium between complexing ligands. As a consequence, the free metal ion is present in a relatively low percentage compared to the total dissolved metal (13).

Table 5. Results from Spearman's rho non-parametric test for correlation between effluent heavy metal concentrations and 48-h $\mathrm{LC}_{50}$ P. monodon (PM) data

\begin{tabular}{cccccccccc}
\hline \multirow{2}{*}{ Spearman's rho correlation } & \multicolumn{3}{c}{ Cr } & \multicolumn{3}{c}{ NI } & \multicolumn{2}{c}{ CU } & \multicolumn{3}{c}{ AS } \\
\cline { 2 - 10 } & PM & PV & PM & PV & PM & PV & PM & PV \\
\hline \multirow{2}{*}{ Correlation Coefficient Sig. (2 Tailed) } & .098 & -.342 & .109 & -.436 & -.577 & -.247 & .310 & .548 \\
& .818 & .408 & .797 & .280 & .134 & .555 & .456 & .160 \\
\hline
\end{tabular}




\section{CONCLUSION}

Significant correlation was found between PM acute toxicity data and effluent sample toluene concentrations only (Spearman's rho correlation coefficient $=0.857, \mathrm{p}<0.05)$. No significant correlation was found between acute toxicity data and concentrations of any of the heavy metals ( $\mathrm{Cr}, \mathrm{Ni}, \mathrm{Cu}$, and $\mathrm{As}$ ), for PM. There currently is very little data to support correlations between individual concentrations of natural gas drilling platform effluents and acute toxicity. The potential interactive effects of the individual components in this complex mixture, e.g. synergism, antagonism and potentiation, would make it very unlikely that any one component, however toxic individually, could play a significant part in the overall toxicity. Additionally, the lack of correlation may be due to a low acute toxicity of the individual toxicants, e.g. heavy metals, particularly at the levels found in this study. This also means that toxicity testing, e.g. WETT, which takes into account the sum toxicity of a mixture, is much more useful for monitoring the quality, i.e. toxicity, of wastewater effluent and the potential effects on receiving waters.

\section{REFERENCES}

1. Min K. Wastewater Pollution in China. [access: 4 July 2008]; Available from: http://www.dbc.uci.edu/ sustain/ suscoasts/krismin.html

2. Rita Comotto Bahner DJH, ASTM Committee E-47 on Biological Effects and Environmental Fate. Aquatic toxicology and hazard assessment: eighth symposium : a symposium, Issue 891. Baltimore, MD: ASTM International; 1985.
3. Jin H, Yang X, Yin D, Yu H. A Case Study on Identifying the Toxicant in Effluent Discharged from a Chemical Plant. Marine Pollution Bulletin. 1999;39(1-12):122-5.

4. Holdway DA. The acute and chronic effects of wastes associated with offshore oil and gas production on temperate and tropical marine ecological processes. Marine Pollution Bulletin. 2002;44(3):185-203.

5. Julie A Hall LG. Standard Methods for Whole Effluent Toxicity Testing: Development and Application. New Zealand: National Institute of Water \& Atmospheric Research Ltd1998 November 1998.Adams MS, Stauber JL, Binet MT, Molloy R, Gregory D. Toxicity of a secondary-treated sewage effluent to marine biota in Bass Strait, Australia: Development of action trigger values for a toxicity monitoring program. Marine Pollution Bulletin. 2008;57(6-12):587-98.

6. Promsoongwong S. "Appropriate Test Conditions For Industrial Whole Effluent Toxicity Testing In Giant Freshwater Prawn, Macrobrachium rosenbergii.": Mahidol University. 2004.

7. Technical Support Document for the Code of Practice for Produced Water from Oil and Gas Operations in the Gulf of Thailand. California. Tetra Tech, Inc.2002 June 28

8. Surapukdee t. Whole Effluent Toxicity Test Species Comparisons to Detrmine Whether Responses Seen in Penaeus monodon and Lates calcarifer are Representative for Native Species in The Gulf of Thailand. Bangkok: Asian Institute of Technology. 2004.

9. USEPA. Understanding and Accounting 
for Method Variability in Whole Effluent Toxicity Applications Under the National Pollutant Discharge Elimination System. Washington DC: U.S. EPA Office of Wastewater Management; 2002. p. 185.

10. S. Akbari aTL, and M. Shariff. Toxicity of water soluble fractions of crude oil to fish, lutjanus argentimaculatus and shrimp, Penaeus monodon. Iranian Journal of Science \& Technology, Trans A. 2003; Volume 28, Number A1:7.
11. USEPA. Methods for measuring the acute toxicity of effluents and receiving waters to freshwater and marine organism, fifth edition. Washington, DC: U.S. EPA office of water (4303T); 2002.

12. Adebayo A. Otitoloju OKE, Adesola O. Osibona. Biological responses in edible crab, Callinectes amnicola that could serve as markers of heavy metals pollution. Springer Science Business Media, LLC. 2009: 29. effects on receiving waters. 